\title{
PREDIKTORI STRATEGIJA REŠAVANJA VRŠNJAČKIH KONFLIKATA U ADOLESCENCIJI: ŠTA SE KRIJE IZA PREFERIRANIH STRATEGIJA?
}

Vršnjački konflikti i način njihovog rešavanja zauzimaju centralno mesto u vršnjačkim odnosima adolescenata. Strategije koje se koriste za rešavanje konflikata značajno oblikuju vršnjačke odnose i ostvaruju važan uticaj na socijalno i emocionalno funkcionisanje adolescenta.

Predmet ovog istraživanja predstavlja ispitivanje značaja nekih emocionalnih kompetencija (emocionalnog razumevanja, empatije, emocionalne regulacije i prepoznavanja emocija) u predikciji različitih strategija. Uzorak u ovom istraživanju sastojao se od 350 ispitanika prosečnog uzrasta od 12 godina, ujednačenog po polu. U cilju ispitivanja značaja i učešća odabranih prediktorskih varijabli u predikciji strategija za rešavanje vršnjačkih konflikata primenjena je multivarijatna analiza kovarijanse (MANCOVA).

Rezultati pokazuju da visoka emocionalna kontrola ima značajnu ulogu u svim strategijama, s tim da je kod agresivnih strategija ta veza negativna. Razumevanje emocija pokazalo se ključnim u strategijama usmerenim na rešavanje problema i u asertivnim strategijama. Prepoznavanje emocija na osnovu facijalnih izraza pokazala se kao značajan prediktor jedino kod asertivnih strategija za rešavanje konflikata. Empatija se pokazala kao ključni prediktor strategija usmerenih na rešavanje problema i prediktor strategija traženja socijalne podrške.

Rezultati govore u prilog tezi da emocionalna kompetencija predstavlja važnu odrednicu strategija za rešavanje konflikata.

Ključne reči: adolescencija, strategije za rešavanje konflikata, emocionalna kompetencija, emocionalna kontrola, empatija, prepoznavanje emocija, razumevanje emocija.

\section{UVOD}

Tokom perioda adolescencije, uz sve ostale nagle očekivane razvojne turbulencije, promene u socijalnoj mreži bivaju sve izrazitije. Kvalitet odnosa sa "značajnim drugima" se ubrzano menja, postavljajući zahteve pred adolescenta da

* jelica.petrovic@ff.uns.ac.rs 
im se prilagodi. Pojačana potreba za autonomijom jeste važna tema u adolescenciji, dok, s druge strane, potreba da se bude prihvaćen unutar vršnjačke grupe postaje jedan od najvažnijih ciljeva. Upravo ovo balansiranje na relaciji pripadnostautonomija često otvara put potencijalnim konfliktima u svim važnim odnosima, uključujući roditelje, vršnjake i partnere (Lohman, Jarvis, 2000). Istraživanja pokazuju da vršnjaci u adolescenciji postaju veoma važan izvor socijalne podrške, ali i negativne razmene, uključujući tu i konflikte (Petrović, 2006).

Konflikti generalno predstavljaju vrstu interakcije u kojoj postoji inkompatibilnost u ponašanju ili ciljevima (Laursen \& Hafen, 2010). Očekivano je da $\mathrm{u}$ adolescenciji teme konflikata sve češće budu vezane za neslaganje $\mathrm{u}$ uverenjima i ponašanju, te $u$ tom smislu već liče na teme konflikata kod odraslih. Rezultati istraživanja sprovedenog na uzorku mlađih adolescenata iz Srbije pokazuju da su razlozi zbog kojih najčešće dolazi do sukoba među vršnjacima zadirkivanje, neumesne šale, provociranje, vređanje, ogovaranje, sukob mišljenja i kompetencija (Petrović, 2010). U svakom slučaju, vršnjački konflikti i način njihovog rešavanja postaju centralno mesto u vršnjačkim odnosima adolescenata. Strategije koje se koriste za rešavanje konflikata utiču na ishode samog vršnjačkog konflikta i time značajno oblikuju njihove odnose i ostvaruju važan uticaj na socijalno i emocionalno funkcionisanje adolescenta (Rinaldi\&Cheong, 2020; Petrović, 2015). Strategije rešavanja konflikata predstavljaju način na koji se ponašamo unutar konfliktnih situacija (Kim-Jo et al., 2010). Ukoliko se konflikti među vršnjacima ne rešavaju neposredno i vešto (u smislu korišćenja adaptivnih, konstruktivnh strategija), mogu imati razorno dejstvo po njihov odnos (Zimmermann, 2003; Oswald et al., 2004). S druge strane, uspešna rezolucija konflikata donosi veliki razvojni potencijal, te interpersonalni odnosi tako dobijaju na kvalitetu (Leadbeater et al.,2006). Brojni autori tvrde da se strategije rešavanja konflikata ugrubo mogu podeliti samo u dve kategorije: upuštanje u konflikt $\mathrm{i}$ izbegavanje konflikta (Wilmot \& Hocker, 1998). Nešto razrađeniji modeli uključuju pregovaranje (pravljenje kompromisa i uključivanje treće strane), neupuštanje (povlačenje i izbegavanje) i submisivnost, tj. popuštanje (Jensen-Campbell et al., 1996). Na slične kategorije nailazimo i u drugim istraživanjima. Tako se u njima pominju, na primer, problem usmerene strategije (ponašanja sa ciljem nalaženja rešenja problema u direktnoj komunikaciji), kontrolišuća strategija (čvrsto zauzimanje sopstvenog stanovišta i pokušaji kontrolisanja situacije) i nekonfrontiranje (povlačenje iz situacije i sakrivanje sopstvenih osećanja) (Putnam $\&$ Wilson, 1982). S obzirom na to da strategije rešavanja konflikata zavise od vrste situacije i tipa interpersonalnog odnosa, nije lako apriori odrediti koje su strategije 
konstruktivne, a koje ne. Ono što je sigurno jeste da negovanje bilo kog rigidnog obrasca u svim konfliktnim situacijama svakako nije adaptivno. Na primer, izbegavanje konflikata može biti veoma korisna strategija u situaciji vršnjačkog nasilja. Međutim, ako je to jedina strategija koju osoba koristi u svim interpersonalnim odnosima, ne možemo je smatrati adaptivnom. Ipak, složićemo se sa stanovištem pojedinih autora da konstruktivno rešavanje konflikata svakako podrazumeva, na primer, usmerene strategije za koje se pokazalo da su povezane sa socijalnom adaptacijom (Petrović, 2015) i mentalnim zdravljem (Wheeler et al.,2010; Marceau et al., 2015). U nekonstruktivne strategije svakako spadaju agresivne strategije i ponašanja izbegavanja, jer su povezane sa niskim kvalitetom interpersonalnih odnosa i niskom psiho-socijalnom adaptacijom (Olson \& Braithwaite, 2004; Wheeler et al.,2010; Petrović, 2015; Overall\&McNulty,2017).

$\mathrm{U}$ adolescenciji repertoar strategija rešavanja konflikata postaje bogatiji $\mathrm{u}$ odnosu na prethodni uzrast. Povećava se učestalost konstruktivnih strategija (pregovaranje, kooperacija), a opada učestalost destruktivnih, u prvom redu agresivnih strategija (Noakes \& Rinaldi, 2006; Tamm et al., 2018). Takođe, smanjuje se učestalost traženja intervencije i pomoći od odraslih, jer socijalni svet adolescenata sve manje uključuje odrasle (Laursen\&Collins, 1994). Rezultati istraživanja sprovedenog na uzorku mlađih adolescenata iz Srbije pokazuju da konflikti među vršnjacima nisu visoko frekventni i umerenog su intenziteta, a strategije koje se najčešće koriste unutar konfliktih epizoda jesu konstruktivne strategije za rešavanje vršnjačkih konflikata (asertivne i usmerene na rešavanje problema); zatim slede pasivne strategije (distrakcija i izbegavanje) i traženje socijalne podrške, dok su se kao najmanje preferirane strategije pokazale strategije rešavanja konflikata koje uključuju neki od vidova agresivnog ponašanja (Petrović, 2010). Razlozi za ovaj napredak su mnogobrojni. Prvo, važnost pripadnosti vršnjačkoj grupi rapidno raste, te adolescent pronalazi nove načine da rešava konflikte kako ne bi bio isključen. Drugo, prijateljstva koja se sklapaju u adolescencji mnogo su zrelija i trajnija, što podrazumeva održavanje odnosa koji se temelje na reciprocitetu i saradnji. Svi ovi zadaci stavljaju adolescenta pred nove izazove - da razvija različite socijalne veštine, uključujući i veštine komunikacije i umešnost u sposobnosti rešavanja konflikata (Noakes \& Rinaldi, 2006). Uz to, nova kognitivna i emocionalna razvojna postignuća takođe će omogućiti širi raspon konfliktnih strategija - prepoznavanje i razumevanje emocija je sve bolje (Dunn \& Slomkowski, 1995), empatski potencijal napreduje, a i sposobnost tačne procene i tumačenja socijalnih signala raste (Dodge,1985; Putallaz, 1983). 
Imajući u vidu da konflikti jesu nezaobilazan deo vršnjačkih odnosa, te da strategije koje se koriste za rešavanje konflikata snažno oblikuju kvalitet vršnjačkih odnosa (Rinaldi\&Cheong, 2020), važno je upitati se od čega zavisi preferencija nekih specifičnih strategija? Jasno je da bi spisak ovih faktora bio predugačak, jer je ponašanje $u$ konfliktima uslovljeno kulturološkim faktorima, usvojenim porodičnim modelima, ali i mnogobrojnim ličnim karakteristikama. Kako novija istraživanja markiraju važnost socio-emocionalnih veština u konfliktnim situacijama jer se pokazuju kao ključne za rešavanje konflikata i uspešnu socijalnu adaptaciju (Petrović, 2015; Wang et al, 2020), opredelili smo se za ispitivanje udela ovih faktora $\mathrm{u}$ preferenciji određenih strategija za rešavanje konflikata $\mathrm{u}$ ranoj adolescenciji. Kako bismo bolje razumeli zašto adolescenti biraju specifične strategije za rešavanje konflikata za predmet našeg istraživanja odabrali smo ispitivanje značaja nekih emocionalnih kompetencija u predikciji ovih strategija. Drugim rečima, pitamo se da li se adolescenti koji preferiraju različite strategije za rešavanje konflikata razlikuju po stepenu razvijenosti emocionalnog razumevanja, empatije, emocionalne regulacije i prepoznavanju emocija?

\section{METOD}

\section{Uzorak}

Uzorak u ovom istraživanju sastojao se od 350 ispitanika ranog adolescentnog uzrasta (a to su bili učenici 6. i 7. razreda) iz nekoliko osnovnih škola na teritoriji Novog Sada. Uzorak je bio ujednačen po polu (53.7\% dečaka i $46.3 \%$ devojčica), a prosečan uzrast ispitanika je 12 godina.

\section{Instrumenti}

- Skala strategija za rešavanje konflikata (Petrović, 2010).

Upitnik se sastoji se iz 6 hipotetičkih vinjeta u kojima su opisani konflikti između dva deteta istog pola. Nakon svake hipotetičke priče ponuđeno je 5 grupa strategija za rešavanje konflikta, a zadatak ispitanika bio je da na trostepenoj Likertovoj skali za svaku od strategija proceni koliko je verovatno da bi postupio na svaki od ponuđenih načina. Skala uključuje sledeće strategije:

1. strategije umerene na rešenje problema - "problem solving" (pokušaji dogovora, pregovora i ponude alternativnih rešenja u cilju okončanja konflikta), 
2. asertivne strategije (samouverena komunikacija u cilju borbe za sopstvena prava: objašnjavanje razloga zbog kojih se tuđe ponašanje doživljava kao ometajuće; izražavanje sopstvenog mišljenja, zahteva i osećanja, bez narušavanja prava drugih),

3. socijalna podrška (traženje pomoći ili podrške od treće odrasle osobe roditelja ili nastavnika),

4. agresivne strategije (fizička agresija koja podrazumeva udaranje, štipanje,guranje; verbalna agresija (vikanje, psovanje) i relaciona agresija (ucenjivanje,osveta i socijalna manipulacija),

5. pasivne strategije (distrakcija - skretanje pažnje sa konfliktnog događaja i napuštanje ili izbegavanje konfliktne situacije).

\section{- Zadatak prepoznavanja emocija (Petrović, 2007)}

Zadatak prepoznavanja emocija se sastoji se od 12 crno-belih fotografija formata $8 \times 13 \mathrm{~cm}$ na kojima ženski i muški model izražavaju bazične emocije: sreću, tugu, gađenje, iznenađenje, strah i ljutnju. Ispod svake fotografije ponuđeno je 8 različitih emocija, a zadatak ispitanika je da prepozna emociju sa fotografije, a potom da zaokruži jedan od 8 ponuđenih odgovora. Uz prethodno opisane, ubačene su i emocije ponosa i stida da bi se sprečilo odgovaranje po sistemu eliminacije. Test-retest pouzdanosti na uzorku studenata psihologije iznosila je $r=.96$ za ženski model, a r=.90 za muški model (Petrović i Mihić, 2009).

\section{- $\quad$ Skala emocionalne kompetencije (Petrović, 2010)}

Ova skalu čini 23 stavke, a faktorska analiza pokazala je 3 psihološki prepoznatljive dimenzije koje objašnjavaju 32,79\% varijanse. Sadržaj stavki koje čine prvi faktor odnosi se na prepoznavanje i razumevanje sopstvenih i tuđih emocija, kao i na vrstu osetljivosti na emocionalne signale, te je nazvan razumevanje emocija (primer stavke: "primetim kada se neko ponaša različito od onoga kako se oseća"). Stavke koje čine drugi izolovani faktor govore o nekoj vrsti povišene opšte emocionalnosti i osetljivosti na tuđu patnju, te je on nazvan empatija ("kada je neko tužan, pomislim kako bi meni bilo da sam na njegovom mestu"). Stavke koje čine treći faktor govore o visokoj reagibilnosti, impulsivnosti, te slaboj kontroli afekta, dakle o procesima suprotnim dobroj afektivnoj regulaciji, te je taj faktor nazvan emocionalna disregulacija ("lako se iznerviram"). Vrednosti alfa koeficijenata iznose .628 za prvi faktor, za drugi faktor .651, a za treći .690. 
U cilju ispitivanja značaja i učešća odabranih prediktorskih varijabli u predikciji strategija za rešavanje vršnjačkih konflikata primenjena je multivarijatna analiza kovarijanse (MANCOVA). Prediktorski skup obuhvatao je varijable koje se odnose na emocionalnu kompetenciju ispitanika (emocionalno razumevanje, empatija, emocionalna disregulacija, prepoznavanje emocija). kao i na pol ispitanika. Kriterijske varijable odnose se na strategije rešavanja vršnjačkih konflikata tako da ovaj skup obuhvata 5 varijabli (faktorskih skorova): agresivne strategije, strategije rešavanja problema, asertivne strategije, strategije koje uključuju traženje pomoći od odraslog i pasivne strategije.

\section{REZULTATI}

U tabeli 1 prikazani su rezultati testiranja ukupnog modela

Tabela 1: Testiranje ukupnog modela

\begin{tabular}{llllllll}
\hline Kriterijum & $\mathrm{R}$ & $\mathrm{R} 2$ & $\begin{array}{l}\mathrm{R} 2 \\
\text { prilagođen }\end{array}$ & $\begin{array}{l}\text { Ms } \\
\text { model }\end{array}$ & $\begin{array}{l}\text { Ms } \\
\text { Rezidual }\end{array}$ & $\mathrm{F}$ & $\mathrm{P}$ \\
\hline $\begin{array}{l}\text { agresivne } \\
\text { strategije }\end{array}$ & 0,572 & 0,328 & 0,312 & 14,872 & 0,733 & 20,283 & $\mathbf{0 , 0 0 0}$ \\
\hline $\begin{array}{l}\text { strateg. } \\
\text { rešavanja } \\
\text { problema }\end{array}$ & 0,540 & 0,292 & 0,275 & 13,452 & 0,785 & 17,128 & $\mathbf{0 , 0 0 0}$ \\
\hline $\begin{array}{l}\text { asertivne } \\
\text { strategije }\end{array}$ & 0,392 & 0,154 & 0,134 & 6,654 & 0,877 & 7,579 & $\mathbf{0 , 0 0 0}$ \\
\hline $\begin{array}{l}\text { strateg. } \\
\text { traženja } \\
\text { soc.podrške }\end{array}$ & 0,255 & 0,065 & 0,042 & 2,986 & 1,030 & 2,898 & $\mathbf{0 , 0 0 0}$ \\
\hline $\begin{array}{l}\text { pasivne } \\
\text { strategije }\end{array}$ & 0,236 & 0,056 & 0,033 & 2,595 & 1,052 & 2,465 & $\mathbf{0 , 0 0 2}$ \\
\hline
\end{tabular}

Iz tabele možemo videti da su procenti objašnjene varijanse kriterijuma, a na osnovu prediktora značajni. Taj procenat je najveći za agresivne strategije (33\%) i za strategije rešavanja problema (29\%), nešto manji za asertivne strategije (15\%), dok je najmanji procenat kod strategija traženja socijalne podrške (7\%) i pasivnih strategija (6\%)

U tabeli 2 prikazane su statistički značajne parcijalne korelacije prediktora sa kriterijskom varijablom agresivne strategije. 
Tabela 2: Značajnost prediktora za kriterijum agresivne strategije

\begin{tabular}{lll}
\hline Prediktor varijabla & Beta koeficijent & P \\
\hline emoc. disregulacija & 0,298 & 0,000 \\
\hline empatija & $-0,275$ & 0,000 \\
\hline pol & 0,146 & 0,000
\end{tabular}

Kao najbolji prediktori agresivnih strategija u rešavanju vršnjačkih konflikata izdvojili su se nedostatak emocionalne kontrole (regulacije), empatija i pol.

U tabeli 3 prikazane su statistički značajne parcijalne korelacije prediktora sa kriterijskom varijablom Strategije rešavanja problema.

Tabela 3: Značajnost prediktora za kriterijum Strategije rešavanja problema

\begin{tabular}{lll}
\hline Prediktor varijabla & Beta koeficijent & $\mathbf{P}$ \\
\hline empatija & 0,267 & 0,000 \\
\hline emoc. disregulacija & $-0,251$ & 0,000 \\
\hline emoc. razumevanje & 0,084 & 0,035 \\
\hline
\end{tabular}

Najbolji prediktori strategija rešavanja problema su visoka empatičnost i dobra emocionalna kontrola, dok u manjoj meri u predikciji učestvuje sposobnost emocionalnog razumevanja.

U tabeli 4 prikazane su statistički značajne parcijalne korelacije prediktora sa kriterijskom varijablom asertivne strategije.

Tabela 4: Značajnost prediktora za kriterijum asertivne strategije

\begin{tabular}{lll}
\hline Prediktor varijabla & Beta koeficijent & P \\
\hline emoc. razumevanje & 0,188 & 0,000 \\
\hline emoc. disregulacija & 0,091 & 0,033 \\
\hline prepoznavanje emocija & 0,076 & 0,055 \\
\hline
\end{tabular}

Kao najbolji prediktori asertivnih strategija u rešavanju konflikata sa vršnjacima izdvojili su se emocionalno razumevanje, dobra emocionalna kontrola, kao i tačnost prepoznavanja emocija. 
U tabeli 5 prikazane su statistički značajne parcijalne korelacije prediktora sa kriterijskom varijablom strategije traženja socijalne podrške,

Tabela 5: Značajnost prediktora za kriterijum strategije traženja socijalne podrške

\begin{tabular}{lll}
\hline Prediktor varijabla & Beta koeficijent & $\mathbf{P}$ \\
\hline emoc.disregulacija & $-0,133282$ & 0,003214 \\
\hline empatija & 0,130095 & 0,007782 \\
\hline
\end{tabular}

Kao najbolji prediktori strategije traženja pomoći od odraslih izdvojili su se emocionalna kontrola i empatija.

U tabeli 6 prikazane su statistički značajne parcijalne korelacije prediktora sa kriterijskom varijablom pasivne strategije

Tabela 6: Značajnost prediktora za kriterijum pasivne strategije

\begin{tabular}{lll}
\hline Prediktor varijabla & Beta koeficijent & P \\
\hline emoc. disregulacija & $-0,093089$ & 0,040183
\end{tabular}

Kao jedini značajni prediktor pasivnih strategija izdvaja se emocionalna kontrola.

\section{DISKUSIJA I ZAKLJUČAK}

Kao najbolji prediktori agresivnih strategija u rešavanju vršnjačkih konflikata izdvojili su se nedostatak emocionalne kontrole (regulacije) i empatije, kao i muški pol. Ovaj podatak je u skladu sa nalazima drugih istraživanja (Kaukiainen et al., 1999; Bjorquist et al., 2000). Poznato je da empatija služi kao jedan od inhibitora agresivnosti (Lovett \& Sheffield, 2007; Richarson et al., 1994; Hofman, 2003), te da je agresivno ponašanje često uzrokovano nedostatkom saosećanja i sposobnosti da se zauzme pozicija drugog, a naročito ako se javlja u kombinaciji sa niskom emocionalnom kontrolom. Takođe, veliki broj istraživanja svedoči o tome da je muški pol značajan prediktor agresivnih strategija (Osterman et al., 1997; Xu \& Zhang, 2008; Fung et al.,2009). Sem potencijalnih bioloških rodnih razlika, kao dodatni faktori pominju se izraženija socijalna inteligencija kod devojčica u detinjstvu i adolescenciji (Osterman et al., 1997), kao i viši nivo emocionalne kompetencije (Petrović, 2015). S druge strane, mnogi autori beleže rodne razlike u vrstama agresivnog ponašanja, gde dečaci koriste fizičke, a devojčice više indirektne, relacione forme agresivnih strategija (Swit, 2019). Kako 
su u ovom istraživanju agresivne strategije uključivale sve forme: fizičke, verbalne i relacione strategije, ne možemo biti sigurni da rezultati potvrđuju ovu distinkciju.

Najbolji prediktori problema usmerenih strategija su visoka empatičnost $\mathrm{i}$ dobra emocionalna kontrola, dok u nešto manjoj meri u predikciji učestvuje sposobnost emocionalnog razumevanja. Slično tome, kao najbolji prediktor asertivnih strategija $u$ rešavanju konflikata među vršnjacima izdvojilo se emocionalno razumevanje, emocionalna kontrola i tačnost prepoznavanja emocija. $\mathrm{Na}$ osnovu dobijenih rezultata možemo reći da su ove, konstruktivne strategije rešavanja konflikata, tesno povezane sa visokom emocionalnom kompetentnošću kod adolecenata, što je u skladu sa rezultatima drugih istraživanja (Findlay et al., 2006; Thayer et al.,2008).

Najmanji procenat objašnjene varijanse dobijen je u slučaju strategija traženja socijalne podrške i korišćenja pasivnih strategija. Decu koja u situacijama konflikta sa vršnjacima traže pomoć od odraslih (roditelja, nastavnika) karakteriše dobra emocionalna kontrola i empatija, dok se kao jedini značajni prediktor pasivnih srategija izdvaja visoka emocionalna regulacija. Pretpostavljamo da neke varijable koje nisu bile predmet interesa u ovom istraživanju dodatno objašnjavaju ove strategije, pa bi trebalo dodatno ispitati zbog čega adolescenti preferiraju ove strategije. Iz rezultata istraživanja vidimo da se radi o deci koja imaju visok nivo emocionalne kontrole, pa je moguće da, slično kao kod obrasca izbegavanja afektivne vezanosti, postoji nadregulacija emocija gde je podignut prag tolerancije za one situacije u kojima treba regulisati afekat. Stoga bi bilo korisno ispitati i učešće obrazaca afektivne vezanosti u predikciji ovih strategija. Pasivne strategije su naročito važne jer su vrlo često povezane sa viktimizacijom (Wang et al.,2020), te bi bilo korisno utvrditi i sociometrijski status ove dece. Nedostatak socijalnih veština, kao i poverenje u sopstvenu sposobnost da se primeni neka aktivna strategija u rešavanju konflikata mogli bi biti važni korelati ovih strategija. Svakako da neke druge varijable, iz domena ličnosti, ili iz domena socio-kognitivnih kompetencija mogu imati veću ulogu u njihovoj predikciji.

Ako bismo govorili o posebnim emocionalnim kompetencijama i njihovom značaju za rešavanje konflikata, vidimo da visoka emocionalna kontrola ima značajnu ulogu u svim strategijama, s tim da je kod agresivnih strategija ta veza negativna. S obzirom na to da je inkompatibilnost ciljeva i ponašanja ključna odrednica konflikta, u tim situacijama lako je ući u "spiralu negativnosti" koja može da eskalira i dovede do agresivnih ponašanja. Veliki broj istraživanja pokazuje da sposobnost regulisanja emocija utiče na kvalitet socijalne interakcije, dok je slabo razvijena regulacija emocija često povezana sa agresivnim ponašanjem, smanjenom 
tolerancijom na frustraciju, niskim nivoom kooperativnosti i prosocijalnog ponašanja (Saarni, 1999). Stoga se čine logičnim ovi rezultati koji pokazuju važnost emocionalne kontrole u konfliktnim situacijama, nezavisno od strategije koja se koristi. Modulacija emocionalnog odgovora, njegovog intenziteta i trajanja može biti od ključne važnosti za sprečavanje eskalacije konflikta i na taj način predstavlja nužan preduslov za konstruktivne načine rešavanja konfliktnih situacija. Mnogi autori posebno naglašavaju socijalnu funkciju emocionalne regulacije, definišući je kao sposobnost kontrole emocionalnog odgovora u službi postizanja određenih socijalnih ciljeva (Hubbard \& Coie, 1994), što u adolescentskim vršnjačkim grupama ima posebnu važnost, jer pripadnost grupi postaje dominantan socijalni cilj.

Razumevanje emocija pokazalo se ključnim u strategijama usmerenim na rešavanje problema i asertivnim strategijama. Dakle, preferencija konstruktivnih strategija povezana je sa razumevanjem sopstvenih i tuđih emocija i njihovih uzroka. Stavke koje su činile ovaj faktor uključuju i one koje se odnose na senzitivnost na socijalne signale. Tako možemo reći da adolescenti koji prefereriraju konstruktivne strategije imaju pojačanu sposobnost da na vreme uoče važne socijalne signale, te da ih adekvatno protumače i detektuju emocionalni ton interakcije. Neki autori smatraju da su osobe koje imaju visok nivo potrebe za pripadanjem istovremeno i veoma senzitivne na socijalne signale (Pickett et al., 2004), te bi bilo interesantno proveriti nivo ove potrebe kod adolescenata koji dominantno koriste agresivne i pasivne strategije.

Prepoznavanje emocija na osnovu facijalnih izraza pokazalo se kao značajan prediktor jedino kod asertivnih strategija za rešavanje konflikata, što svedoči o tome da adolescenti koji prefereiraju ovu strategiju u odnosu na ostale ispitanike sa većom tačnošću procenjuju značenje emocionalnih izraza.

Empatija se pokazala kao ključni prediktor strategija usmerenih na rešavanje problema i strategija traženja socijalne podrške. Stavke koji čine ovaj faktor odnose se na razumevanje pozicije drugog, ali i jednu opštu povišenu emocionalnost $\mathrm{u}$ interpersonalnom kontekstu. Možemo zaključiti da empatijski potencijal jeste krucijalan za sve konstruktivne strategije rešavanja konflikata, ali je nedovoljan. Tako iz rezultata vidimo da adolescenti koji imaju visok empatijski potencijal, ali i sposobnost emocionalne regulacije primenjuju problem usmerene strategije, dok adolescenti sa visokim nivoom empatije kod kojih nije izražen visok nivo kontrole traže intervenciju treće strane. Ovaj nalaz je u skladu sa stanovištima autora koji tvrde da previsok nivo empatije može da se doživi kao averzivan i da inhibira forme socijalno kompetentnog ponašanja (Hofman, 2003). U takvim 
situacijama postoji tzv "egocentrični obrt" koji je rezultat povišene opšte emocionalnosti i nedovoljno razvijenih sposobnosti regulisanja emocija. Otud možemo pretpostaviti da adolescenti sa visokim empatijskim potencijalom traže intervenciju treće strane u cilju regulacije sopstvenog afekta.

Konflikti među vršnjacima $u$ adolescenciji predstavljaju nezaobilazan vid socijalne interakcije. Pojava i dejstvo vršnjačkih sukoba nije nužno negativno, jer konflikti imaju izuzetan razvojni potencijal. U konfiktima se stvara tlo za uvežbavanje i praktikovanje važnih socijalnih i emocionalnih veština, za definisanje ličnih granica i odnosa sa vršnjačkom grupom (Nucci et al., 1996). Ono što se čini neophodnim jeste unapređenje strategija za rešavanje konflikata kako bi se ovaj potencijal maksimalno iskoristio. Ovo istraživanje imalo je za cilj da rasvetli šta od emocionalnih kompetencija stoji u osnovi preferencije korišćenja specifičnih strategija u konfliktnim situacijama. Dobijeni rezultati nam tako daju osnov za razmišljanje o kreiranju interventnih programa u smeru unapređenja emocionalnih kompetencija koje nedostaju, jer one definitivno predstavljaju jedan od delova mozaika uspešnog rešavanja konflikata.

Jelica Petrović

PREDICTING CONFLICT RESOLUTION STRATEGIES IN PEER RELATIONS IN ADOLESCENCE: WHAT LIES BEHIND THESE STRATEGIES?

\section{Summary}

Peer conflicts occupy a central place in adolescent peer relationships. Conflict resolution strategies significantly shape relationships and have an important impact on the social and emotional functioning of adolescents (Rinaldi \& Cheong, 2020; Petrović, 2015). In adolescence, the repertoire of conflict resolution strategies includes the following: the frequency of seeking intervention and help from adults decreases, the frequency of constructive strategies increases, and the frequency of destructive, primarily aggressive strategies decreases (Noakes \& Rinaldi, 2006; Tamm et al., 2018).

The aimof this research is to examine the importance of emotional competence (emotional understanding, empathy, emotional regulation and emotion recognition) in prediction of different conflict resolution strategies. The sample consisted of 350 subjects, aged 12 years, gender-balanced. In order to examine the significance of selected predictor variables in the prediction of conflict resolution strategies, multivariate covariance analysis (MANCOVA) was applied.

The results show that high emotional regulation plays a significant role in the prediction of all strategies with the lack of emotional regulation being associated with aggressive conflict 
resolution strategies. Emotional regulation is found to be crucial for preventing the escalation of conflict and thus represents a necessary prerequisite for constructive conflict resolution strategies. Understanding emotions has proven to be a significant predictor for problem-solving strategies and assertive strategies. Adolescents who prefer constructive strategies have an enhanced ability to spot important social signals in a timely manner, and to interpret them adequately. Recognition of emotions has been shown to be a significant predictor only in assertive conflict resolution strategies. Empathy has been found to be a key predictor for problem-solving strategies and social support strategies. Empathic potential is crucial for all constructive conflict resolution strategies, but it seems to be insufficient. Adolescents, high in empathy and emotion regulation, prefer problem solving strategy, while adolescents high in empathy, but not in emotional regulation, prefer social support strategy. The results support the thesis that emotional competence is an important determinant of conflict resolution strategies.

Key words: adolescence, conflict resolution strategies, emotional competence, emotional regulation, empathy, emotional understanding, emotion recognition

\section{LITERATURA}

Björkqvist, K., Lagerspetz, K. M. J., \& Kaukiainen, A. (2000). Social intelligence empathy = aggression. Aggression and Violent Behavior, 5 (2), 191-200.

Dodge, K. A. (1985). Attributional bias in aggressive children. In: P. C. Kendall (Ed.). Advances in cognitive and behavioral research and therapy. San Diego, CA: Academic Press, 73-110

Dunn, J., Slomkowski, C. (1995). Conflict and development of self understanding.

In: C. U. Schantz \& W. W. Hartup (Eds.). Conflict in child and adolescent development. Cambridge: Cambridge University Press, 70-92.

Findlay, L. C., Girardi, A. \& Coplan, R. J. (2006). Links between empathy, social behavior, and emotional understanding in early childhood. Canada: Carleton University

Fung, A. L. C., Raine, A., \& Gao, Y. (2009). Cross-cultural generalizability of the reactive-proactive aggression questionnaire (RPQ).Journal of Personality Assessment, 91,473-479

Hofman, M. L. (2003). Empatija i moralni razvoj - značaj za brigu i pravdu. Beograd: Dereta.

Hubbard, J., Coie, J. (1994). Emotional Correlates of Social Competence in Children's Peer Relationships. Merrill-Palmer quarterly 40:1-20

Jensen-Campbell, L. A., Graziano, W. G., \& Hair, E. C. (1996). Personality and relationships as moderators of interpersonal conflict in adolescents. MerrillPalmer Quarterly, 42, 148-163. 
Kaukiainen, A., Bjorkqvist, K., Lagerspetz, K. M. J., Osterman, K., Salmivalli, C., Rothberg, S., Ahlbom, A. (1999). The relationship between social intelligence, empathy and three types of aggression. Aggressive Behavior, $25,81-89$.

Kim-Jo, T., Benet-Martinez, V., \& Ozer, D. J. (2010). Culture and interpersonal conflict resolution styles: Role of acculturation. Journal of Cross-Cultural Psychology,41(2), 264-269.

Laursen, B., \& Hafen, C. (2010). Future Directions in the Study of Close Relationships: Conflict is Bad (Except When It's Not). Social development, 19(4), 858-872.

Laursen, B., Collins, A. W. (1994). Interpersonal conflict during adolescence. Psychological Bulletin, 115 (2), 197-209.

Leadbeater, B. J., Ohan, J. L., \& Hoglund, W. L. (2006). How children's justifications of the 'best thing to do' in peer conflicts relate to their emotional and behavioral problems in early elementary school. MerrillPalmer Quarterly, 52, 721-754.

Lohman, B., Jarvis, P. (2000). Adolescent stressors, coping strategies, and psychological he-alth studied in the family context. Journal of Youth and Adolescence, 29, pp. 15-43.

Lovett, B. J., Sheffield, R. A. (2007). Affective empathy deficits in aggressive children and adolescents: A critical review. Clinical Psychology Review, $27,1-13$.

Marceau, K., Zahn-Waxler, C., Shirtcliff, E. A., Schreiber, J. E., Hastings, P., \& Klimes-Dougan, B. (2015). Adolescents', mothers', and fathers' gendered coping strategies during conflict: Youth and parent influences on conflict resolution and psychopathology. Development and Psychopathology, 27, 1025-1044.

Noakes, M. A., \& Rinaldi, C. M. (2006). Age and gender differences in peer conflict. Journal of Youth and Adolescence, 35 (6), 881-891.

Nucci, L. P., Killen, M., \& Smetana, J. G. (1996). Autonomy and the personal: Negotiation and social reciprocity in adult- -child social exchanges. In: M. Killen (Ed.). New Directions for Child Development. Children's autonomy, social competence, and interactions with adults and other children: Exploring connections and consequences (No. 73, pp. 7-24). San Francisco: Jossey-Bass. 
Olson, L. N., \& Braithwaite, D. O. (2004). "If you hit me again, I'll hit you back:" Conflict management strategies of individuals experiencing aggression during conflicts. Communication Studies, 55(2), 271-285.

Osterman, K., Bjorkquist, K., Lagerspetz, K. M., Landau, S. F., Fraczek, A., Pastorelli, C. (1997). Sex Differences in Styles of Conflict Resolution: A Developmental and Cross-Cultural Study with Data From Finland, Israel, Italy, and Poland. In: D. P. Fry \& Bjorkquist, K. (Eds.). Cultural variation in conflict resolution (185-197). Mahwah, NJ: Lawrence Erlbaum Associates.

Oswald, D.L., Clark, E.M., \& Kelly, C.M. (2004). Friendship Maintenance: An Analysis of Individual and Dyad Behaviors. Journal of Social and Clinical Psychology, 23 (3), 413-441.

Overall, N. C., \& McNulty, J. K. (2017). What type of communication during conflict is beneficial for intimate relationships? Current Opinion In Psychology, 13, 1-5.

Petrović J., Mihić I. (2009). Polne razlike u sposobnosti prepoznavanja emocija na osnovu facijalnih ekspresija muškog i ženskog modela (u periodu rane adolescencije). Godišnjak Filozofskog fakulteta u Novom Sadu, 34 (2), 1526.

Petrović, J. (2006). Percepcija kvaliteta socijalnih odnosa u adolescenciji. Teme, 2, 291-306.

Petrović, J. (2007). Emocionalni temelji socijalne kompetencije. Beograd: Zadužbina Andrejević

Petrović, J. (2010). Karakteristike vršnjačkih konflikata u adolescenciji. Primenjena psihologija, 3, 223-238

Petrović, J. (2015). Konflikti u adolescenciji: od socijalne adaptacije do destrukcije. Novi Sad: Filozofski fakultet.

Pickett, C. L., Gardner, W. L., \& Knowles, M. (2004). Getting a cue: The need to belong and enhanced sensitivity to social cues. Personality and Social Psychology Bulletin, 30, 1095-1107.

Putallaz, M. (1983). Predicting children's sociometric status from their behavior. Child Development, 54, 1417-1422.

Putnam, L.L., \& Wilson, C.E. (1982). Communication strategies in organizational conflicts: Reliability and validity of a measurement scale . In M. Burgoon (Ed.), Communication Yearbook 6. Beverly Hills: Sage Publications, 629652. 
Richardson, D. R., Hammock, G. S., Smith, M. S., Gardner, W. \& Singo, M. (1994). Empathy as a cognitive inhibitor of interpersonal aggression. Aggressive Behavior, 20, 275-289.

Rinaldi, C.M. and Cheong, C. (2020). Peer Conflict Resolution. In The Encyclopedia of Child and Adolescent Development (eds S. Hupp and J. Jewell).

Saarni, C. (1999). The development of emotional competence. New York: Guilford Press.

Swit, C. S. (2019). Understanding the distinctive differences between relationally and physically aggressive behaviours used in early childhood contexts. Early Education and Development. Advance online publication.

Tamm, A., Tulviste, T., Urm, A. (2018). Resolving conflicts with friends: Adolescents' strategies and reasonsbehind these strategies. Journal of Adolescence 64,72-80

Thayer, S. M., Updegraff, K. A., \& Delgado, M. Y. (2008). Conflict resolution in Mexican American adolescents' friendships: Links with culture, gender and friendship quality. Journal of Youth and Adolescence, 37(7), 783-797.

Wang, Z., Chen, X., Liu, J., Bullock, A., Li, D., Chen, X., French, D. (2020). Moderating role of conflict resolution strategies in the links between peer victimization and psychological adjustment among youth. Journal of Adolescence 79: 184-192

Wheeler, L. A., Updegraff, K. A., \& Thayer, S. M. (2010). Conflict Resolution in Mexican-origin couples: Culture, gender, and marital quality. Journal of Marriage and Family, 72(4), 991-1005.

Wilmot, W. W., Hocker, J. L. (1998). Interpersonal conflict. Boston: McGraw Hill $\mathrm{Xu}$, Y., \& Zhang, Z. (2008). Distinguishing proactive and reactive aggres-sion in Chinese children.Journal of Abnormal Child Psychology, 36, 539-552.

Zimmermann, P. (2003). Attachment representations and characteristics of friendship relations during adolescence. Journal of Experimental Child Psychology, 88, 83-101. 